$\underline{\text { Original Article }}$

\title{
PHYTOCHEMICAL TO INTERACT WITH NLS BINDING SITE ON IMA3 TO INHIBIT IMPORTIN A/B1 MEDIATED NUCLEAR IMPORT OF SARS-COV-2 CARGO
}

\author{
BHARATH B. R. ${ }^{*}$, HRISHIKESH DAMLE ${ }^{2}$, SHIBAN GANJU' ${ }^{2}$, LATHA DAMLE${ }^{1}$ \\ ${ }^{1}$ Atrimed Biotech LLP, BBC, Electronics City Phase 1, Electronic City, Bengaluru, Karnataka 560100, ${ }^{2}$ Atrimed Pharmaceuticals Pvt. Ltd. 14 \\ Floor no 29, Prestige Meridian Tower 2, 30, Mahatma Gandhi Rd, KG Halli, D' Souza Layout, Ashok Nagar, Bengaluru, Karnataka 560001 \\ Email: bharath.br@atrimed.com
}

Received: 06 May 2020, Revised and Accepted: 09 Jun 2020

\begin{abstract}
Objective: Ivermectin is an FDA-approved, broad-spectrum anti-parasitic agent. It was originally identified as an inhibitor of interaction between the human 29 immunodeficiency virus-1 (HIV-1) integrase protein (IN) and the Importin (IMP) $\alpha / \beta 130$ heterodimers, which are responsible for IN
\end{abstract} nuclear import. Recent studies demonstrate that ivermectin is worthy of further consideration as a possible SARS-CoV-2 antiviral.

Methods: We built the pathogen-host interactome and analyzed it using PHISTO. We compared Ivermectin and plant molecules for their interaction with Importin $\alpha 3$ (IMA3) using molecular docking studies.

Results: A phytochemical ATRI001 with the lowest binding energy-7.290 Kcal/mol was found to be superior to Ivermectin with binding energy$4.946 \mathrm{Kcal} / \mathrm{mol}$.

Conclusion: ATRI001 may be a potential anti-SARS-CoV-2 agent; however, it requires clinical evaluation.

Keywords: Ivermectin, SARS-CoV-2, IMA3, Phytochemical and Molecular docking

(C) 2020 The Authors. Published by Innovare Academic Sciences Pvt Ltd. This is an open access article under the CC BY license (http://creativecommons.org/licenses/by/4.0/) DOI: http://dx.doi.org/10.22159/ijpps.2020v12i8.38184. Journal homepage: https://innovareacademics.in/journals/index.php/ijpps.

Speedy peer review was done as the subject of the manuscript was related with pandemic.

\section{INTRODUCTION}

Severe acute respiratory syndrome coronavirus-2 (SARS-CoV-2), the causative agent of COVID-19 pandemic, is a single-stranded positivesense RNA virus, which is closely related to earlier SARS-CoV [1] Available reports on SARS-CoV proteins have demonstrated a potential role of IMP $\alpha / \beta$ during infection in the signal-dependent nucleocytoplasmic shutting of the SARS-CoV Nucleocapsid protein [2-5], that may cause significant impact on host cell division [6, 7]. Additionally, the SARS-CoV accessory protein ORF6 has been shown to antagonize the antiviral activity of the STAT1 transcription factor by sequestering IMP $\alpha / \beta 1$ on the rough ER/Golgi membrane [8]. These reports suggest that nuclear transport inhibitory activity of ivermectin may be effective against SARS-CoV-2.

Seven human isoforms of IMA mediate nuclear import of cargo into the tissue in an isoform-specific manner. Active transport of proteins from the cytoplasm to the nucleus is mediated by a family of nuclear transport receptors known as importins (or karyopherins), together with several ancillary proteins, including nucleoporins and Ran [810]. The classical nuclear import pathway is initiated by a unique NLS on importin $\alpha$ [11]. The cargo-IMA complex gets transported through the nuclear pore by building a heterotrimer complex with importin $\beta$ (IMB), necessitating interactions with FG repeat regions on nucleoporin proteins $[12,13]$.

Once the complex traverse the nuclear envelope, the RanGTP dissociates the complex, and the import receptors get recycled back to the cytoplasm for the next rounds of transport [14-17]. IMA includes importin $\beta$-binding (IBB) domain at its N-terminal and NLS binding domain towards C-terminal featuring ten armadillo (ARM)-repeat motifs [18]. Most commonly, the cargo NLS binds on the concave site of the ARM repeats and involves interactions at either the major site through ARM repeats 2-4 or minor site ARM repeats 6-8. The classical monopartite NLSs (e. g., SV40T-ag [19]) are known to interact with the major site, while, human phospholipid scramblase [20] and TPX2 [21] with the minor site. The classical bipartite NLSs like nucleoplasmin interact with both the major and minor sites [19]. Although this process has been well characterized for the importin $\alpha 1$ adaptor protein, many nuclear proteins exhibit specificity for other importin $\alpha$ isoforms.

For example, both RCC1 [22], HIV-1 integrase [23], W protein of Nipah virus (NiV) [24, 25], avian influenza PB2 viral polymerase subunit [26] and SARS-CoV2 bind specifically to importin $\alpha 3$. Whereas, STAT1, a signaling molecule in the innate immune system response, binds specifically to the convex $\mathrm{C}$-terminal surface of importin $\alpha 5, \alpha 6$, and $\alpha 7[27,28]$.

A wide variety of active phytochemicals have been found to have therapeutic applications against viruses. The antiviral mechanism of these agents may be explained by their antioxidant activities, scavenging capacities, inhibition of DNA, RNA synthesis, or blocking of viral reproduction. Epidemiological and experimental studies have revealed that a large number of phytochemicals have promising antiviral activities [29].

More than 220 Phyto-compounds evaluated by others for activity against anti-severe acute respiratory syndrome-associated coronavirus (SARS-CoV) using a cell-based assay measuring the SARS-CoV-induced cytopathogenic effect on Vero E6 cells and compounds [30-32] showed excellent activities [33, 34]. The bioactive compounds with anti-SARS$\mathrm{CoV}$ activity in the mmol range included abietane and labdane-type diterpenes sesquiterpenes and lupane-type triterpenes [34].

The current study is aimed to screen a library of plant small molecules library against IMA3 using molecular docking studies. The plant small molecule library developed in-house, consists of 4,08,000 small molecules, which are classified using physicochemical parameters as major classifiers.

\section{MATERIALS AND METHODS}

Topological analysis of pathogen-host interactome (PHI)

The drug target identification and validation were carried out using a network-based topological analysis method using a web-based application Pathogen-Host Interaction Search Tool (PHISTO) available at the URL: http://www.phisto.org/browse.xhtml\#. PHISTO is the most com- 
prehensive pathogen-human protein-protein interaction database on the web. It is used to explore molecular connectivities between the pathways in SARS-CoV and Human interaction through topological analysis $[35,36]$. The information over the interaction of human IMA3 (Uniprot ID: 000629) was retrieved from PHISTO.

\section{Protein preparation}

The crystal structure of IMA3 was pre-processed for docking studies using the Protein Preparation Wizard [37] available in Schrödinger suite 2019-2. Crystallographic water molecules (water molecules without $3 \mathrm{H}$ bonds) were deleted and hydrogen bonds corresponding to $\mathrm{pH} 7.0$ were added, considering the appropriate ionization states for both the acidic and basic amino acid residues. Missing side-chain atoms were added, and breaks present in the structure were built using Prime v4.0, Schrodinger 2019-2 [38]. Using the OPLS_2005 force field [39] energy of the modeled structure was minimized.

\section{Binding site prediction}

The crystal structure of Hendra virus W protein C-terminus in complex with IMA3 crystal form 2 (PDB ID: 6BWA) and IMA3 in cargo free state (PDB ID: 6BVZ) was superimposed to understand the conformational differences between cargo bound state and free state. The protein structure alignment and superimposition was performed concerning backbone atoms using Schrodinger package Maestro ver9.3.

\section{Ligand preparation}

The three-dimensional conformers of Ivermectin and 4,08,000 small plant molecules in our library were subjected for ligand minimization using the Ligprip application provided in Schrödinger Maestro [39]. The ligand minimization was performed by assigning force field OPLS_2005 and stereoisomers were calculated retaining specific chiralities. The ADME (absorption, distribution, metabolism, and excretion) predictions were done for all ligands using the QikProp package (version 4.6 Schrodinger, LLC, New York, NY, 2015) [40].

\section{Molecular docking}

The crystal structure of human IMA3, an adaptor protein involved in the transport of viral protein from the cytoplasmic compartment of an infected cell into a nuclear compartment through NPCs, was prepared using the Protein Preparation Wizard [41]. The major NLS binding site (137-229) was defined with a $10 \AA$ radius around the selected residues (Asn141, Ser144, Trp179, Asn183, and Asn219) present in the crystal structure which are identified as key residues in SARS_nCoV-2 protein and host IMA3 complex formation and a grid box 20X20X20 $\AA$ was generated at the centroid of the active site for docking. The molecular docking of prepared small molecules over IMA3 was performed using Grid-Based Ligand Docking with Energetics Glide v7.8, Schrodinger 2019-2 [42] in 'High Throughput Virtual Screening' HTVS mode without applying any constraints.
Considering the glide score 13,000 , molecules were shortlisted and subjected for docking in 'standard precision' SP mode. The top molecules with high glide score and Ivermectin were further screened using in 'extra precision' mode. The final best-docked structure was selected using a Glide score function, Glide energy, and Glide E model energy. Finally, the lowest-energy docked complex of three plant molecules and ivermectin were interpreted to derive the conclusion.

\section{RESULTS AND DISCUSSION}

Topological analysis of pathogen-host interactome and drug target identification

A thorough analysis of virus-host interactomes may reveal insights into viral infection and pathogenic strategies $[43,44]$. In the current study, IMA3 centric Virus-Human interactome was built by screening domain interactions between Virus-Human protein-protein interactions (PPIs), as shown in table 1. The list of human viruses, including SARS-CoV is reported to transport their cargo protein through IMA3 (Uniprot ID: 000629) mediated nuclear transportation mechanism. Due to the lack of experimental interaction data on SARS-CoV-2, the significant identity between SARS-CoV (Taxonomy ID: 227859) and SARS-CoV-2 (Taxonomy ID: 2697049) proteomes has encouraged us to considered and the SARS-CoV-Human interactome. Through PHI analysis, it is understood that the transportation of SARS-CoV-2 cargo protein NS6 from the cytoplasmic compartment to the nuclear compartment of the infected host cell is mediated by IMA3 [2,3]. Hence, IMA3 is identified as a potential target and molecular docking was performed.

\section{Binding site prediction}

The human IMA3 has its significant function in nuclear protein import as an adapter protein for nuclear receptor KPNB1. IMA3 binds specifically and directly to substrates containing either a simple or bipartite NLS motif [45]. Docking of the importin/substrate complex to the nuclear pore complex (NPC) is mediated by KPNB1 through binding to nucleoporin FxFG repeats and the complex is subsequently translocated through the pore by an energy-requiring, Randependent mechanism. At the nucleoplasmic side of the NPC, Ran binds to IMB, and the three components separate to get re-exported from the nucleus to the cytoplasm where GTP hydrolysis releases Ran from importin [46]. Hence, the NLS site on IMA3 is very important in nuclear protein import.

As tabulated in table 2, IMA3 Consists of an N-terminal hydrophilic region, a hydrophobic central region composed of 10 ARM repeats, and a short hydrophilic $\mathrm{C}$-terminus. The $\mathrm{N}$-terminal hydrophilic region contains the IBB domain, which is sufficient for binding IMB and essential for nuclear protein import [47]. The IBB domain is thought to act as an intragastric autoregulatory sequence by interacting with the internal autoinhibitory NLS as shown in fig. 1.

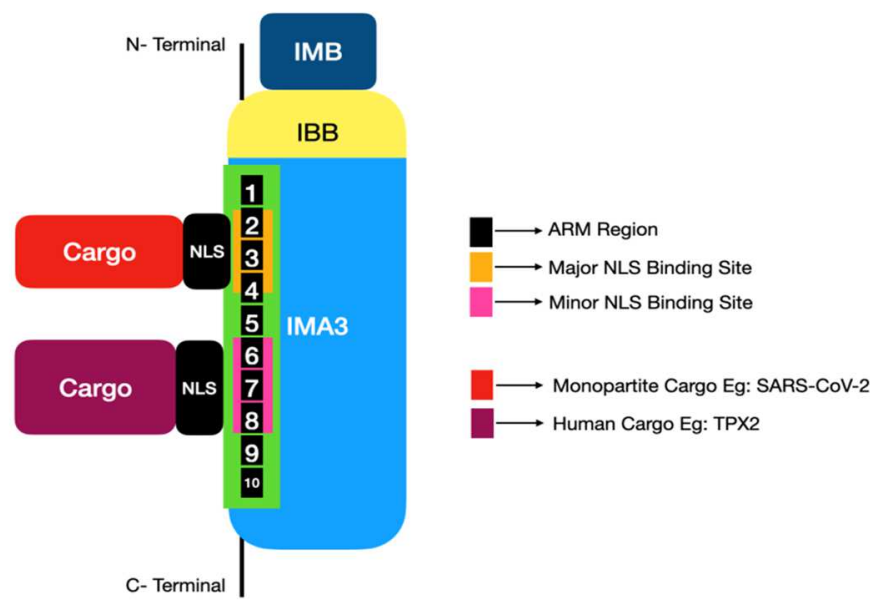

Fig. 1: Simplified representation of IMA3 and nuclear pore complex of cargo containing a classical NLS occurs via importin- $\alpha /$ importin- $\beta$ heterodimer. As noted IMA3 has major and minor NLS binding sites specific to cargo type 
Table 1: Interaction of human importin $\alpha 3$ (Uniprot_ID: 000629) with diverse pathogen proteins

\begin{tabular}{|c|c|c|c|c|c|}
\hline Pathogen & Taxonomy ID & Uniprot ID & Pathogen protein & Experimental method & Pubmed ID \\
\hline Bovine papillomavirus TYPE 1 (BPV 1 ) & 10559 & P03116 & VE1 BPV1 & CIP & 17192311 \\
\hline Deltapapillomavirus 4 & 337052 & P03116 & VE1_BPV1 & CIP & 17192311 \\
\hline Hendra virus ISOLATE & 928303 & P0C1C6 & W_HENDH & TAP & 22810585 \\
\hline \multicolumn{6}{|l|}{ HORSE/AUSTRALIA/HENDRA/1994 } \\
\hline Human herpesvirus 8 & 37296 & 040917 & 040917_HHV8 & Other Methods & 25544563 \\
\hline Human herpesvirus 8 STRAIN GK18 & 868565 & Q2HRC8 & ORF11_HHV8P & ACT & 25544563 \\
\hline Human immunodeficiency virus 1 (HIV1) & 11676 & B9A2Q4 & B9A2Q4_9HIV1 & Y2H, CIP, NMR & $\begin{array}{l}8659115, \\
9548947, \\
8105392, \\
9282826, \\
9918876\end{array}$ \\
\hline HIV1 & 11676 & Q79822 & Q79822_9HIV1 & Y2H, CIP, NMR & $\begin{array}{l}8659115 \\
9548947\end{array}$ \\
\hline HIV1 & 11676 & Q71B33 & Q71B33_9HIV1 & Y2H, CIP, NMR & $\begin{array}{l}8659115 \\
9548947\end{array}$ \\
\hline HIV1 & 11676 & Q72874 & Q72874_9HIV1 & FT, imaging technique & $\begin{array}{l}10366569 \\
12414950\end{array}$ \\
\hline HIV1 & 11676 & Q77YF8 & Q77YF8_9HIV1 & pull down & 22174317 \\
\hline HIV1 ISOLATE BRU & 11686 & P04620 & REV_HV1BR & pull down & 22174317 \\
\hline HIV1 ISOLATE HXB2 & 11706 & P04618 & REV_HV1H2 & ACT & 22174317 \\
\hline HIV1 ISOLATE HXB2 & 11706 & P04585 & POL_HV1H2 & ATC, pull down & 20554775 \\
\hline HIV1 ISOLATE HXB2 & 11706 & P69726 & VPR_HV1H2 & ATC & 20554775 \\
\hline Influenza A virus STRAIN & 387139 & I6TAH8 & I6TAH8_I68A0 & ATC & 28169297 \\
\hline \multicolumn{6}{|l|}{ A/AICHI/2/1968 (H3N2) } \\
\hline Influenza A virus STRAIN A/PUERTO & 211044 & P03466 & NCAP_I34A1 & pull down, ATC & 12740372 \\
\hline RICO/8/1934 (H1N1) & & & & & 28169297 \\
\hline $\begin{array}{l}\text { Influenza A virus STRAIN A/PUERTO } \\
\text { RICO/8/1934 (H1N1) }\end{array}$ & 211044 & P03428 & PB2_I34A1 & ATC & 28169297 \\
\hline $\begin{array}{l}\text { Influenza A virus STRAIN A/PUERTO } \\
\text { RICO/8/1934 (H1N1) }\end{array}$ & 211044 & P03433 & PA_I34A1 & $\mathrm{ABC}$ & 26789921 \\
\hline $\begin{array}{l}\text { Influenza A virus STRAIN A/UDORN/1972 } \\
\text { (H3N2) }\end{array}$ & 385599 & Q20MD0 & Q20MD0_9INFA & Other Methods & 17376915 \\
\hline $\begin{array}{l}\text { Influenza A virus STRAIN } \\
\text { A/VICTORIA/3/1975 (H3N2) }\end{array}$ & 392809 & H9XIJ5 & H9XIJ5_I75A3 & $\begin{array}{l}\text { Molecular sieving, pull } \\
\text { down, x-ray crystallog- } \\
\text { raphy }\end{array}$ & 25599645 \\
\hline $\begin{array}{l}\text { Influenza A virus STRAIN A/Wilson- } \\
\text { Smith/1933 (H1N1) }\end{array}$ & 381518 & P03427 & PB2_I33A0 & CIP & 25464832 \\
\hline $\begin{array}{l}\text { Influenza A virus STRAIN A/Wilson- } \\
\text { Smith/1933 (H1N1) }\end{array}$ & 381518 & P15682 & NCAP_I33A0 & CIP & 25464832 \\
\hline $\begin{array}{l}\text { Influenza A virus STRAIN A/Wilson- } \\
\text { Smith/1933 (H1N1) }\end{array}$ & 381518 & P03470 & NRAM_I33A0 & CIP & 25464832 \\
\hline $\begin{array}{l}\text { Influenza A virus STRAIN A/Wilson- } \\
\text { Smith/1933 (H1N1) }\end{array}$ & 381518 & B4URF7 & B4URF7_9INFA & ACT, ATC & $\begin{array}{l}26651948 \\
28169297\end{array}$ \\
\hline JC polyomavirus & 10632 & Q9DUG7 & Q9DUG7_POVJC & TAP & 22810586 \\
\hline Macaca mulatta polyomavirus 1 & 1891767 & P03070 & LT_SV40 & ELISA, TAP, pull down & $\begin{array}{l}9168958, \\
22810586 \\
20701745\end{array}$ \\
\hline Macaca mulatta polyomavirus 1 & 1891767 & Q9DH70 & Q9DH70_SV40 & $\mathrm{Y} 2 \mathrm{H}$ & $\begin{array}{l}9168958, \\
12740372\end{array}$ \\
\hline Merkel cell polyomavirus & 493803 & B8ZX42 & B8ZX42_9POLY & TAP & 22810586 \\
\hline $\begin{array}{l}\text { Murid herpesvirus } 4 \text { (Murine herpesvirus } \\
68 \text { ) }\end{array}$ & 33708 & 041946 & 041946_MHV68 & & 22028648 \\
\hline Nipah virus & 121791 & Q997F2 & V_NIPAV & TAP & 22810585 \\
\hline Nipah virus & 121791 & P0C1C7 & W_NIPAV & TAP & 22810585 \\
\hline Plasmodium yoelii yoelii & 73239 & P06914 & CSP_PLAYO & pull down & 17981117 \\
\hline $\begin{array}{l}\text { Severe acute respiratory syndrome } \\
\text { (SARS) coronavirus }\end{array}$ & 227859 & P59634 & NS6_CVHSA & $\mathrm{Y} 2 \mathrm{H}$ & 17596301 \\
\hline Yersinia pestis & 632 & Q8D1P8 & Q8D1P8_YERPE & Y2H, Pooling approach & 20711500 \\
\hline
\end{tabular}

Table 2: List of molecular features and functional sites on human IMA3

\begin{tabular}{lll}
\hline Feature key & Description & Position(s) on 000629 \\
\hline Domain & IBB & $2-58$ \\
Repeat & ARM 1, Truncated & $66-106$ \\
Repeat & ARM 2 & $107-149$ \\
Repeat & ARM 3 & $150-194$ \\
Repeat & ARM 4 & $195-233$ \\
Repeat & ARM 5 & $234-278$ \\
Repeat & ARM 6 & $279-318$ \\
Repeat & ARM 7 & $319-360$ \\
Repeat & ARM 8 & $361-400$ \\
Repeat & ARM 9 & $401-443$ \\
Repeat & ARM 10; Atypical & $447-485$ \\
Region & NLS binding site (major) & $137-229$ \\
Region & NLS binding site (minor) & $306-394$ \\
Motif & Nuclear localization signal & $43-52$ \\
\hline
\end{tabular}


Binding of KPNB1 probably overlaps the internal NLS and contributes to a high affinity for cytoplasmic NLS-containing cargo substrates [48]. After dissociation of the importin/substrate complex in the nucleus the internal autoinhibitory NLS contributes to a low affinity for nuclear NLS-containing proteins. The major and minor NLS binding sites are mainly involved in recognition of simple or bipartite NLS motifs. As described by Elena et al., in 1998 [49], structurally located within a helical surface groove, they contain several conserved Trp and Asn residues of the corresponding third helices
(H3) of ARM repeats which mainly contribute to binding as shown in fig. 1. The secondary structure superimposition of the two IMA3 structures in cargo bounded and Free State reveals a global rootmean-square deviation (RMSD) of $1.27 \AA$. And the major RMSD contribution was observed at the ARM2-3 position because of the remarkable conformational change in the loop at the NLS site, as shown in fig. 2A-2C. Hence the amino acids at the ARM2-3 region (Asn141, Ser144, Trp179, Asn183, and Asn219) were identified as a key binding site residue.
A

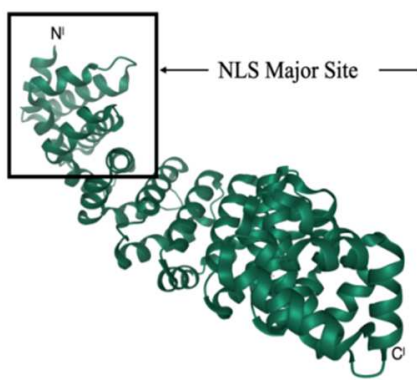

B

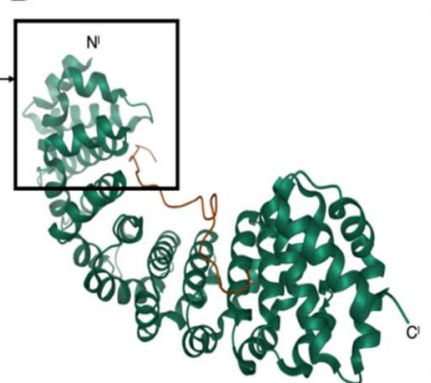

C

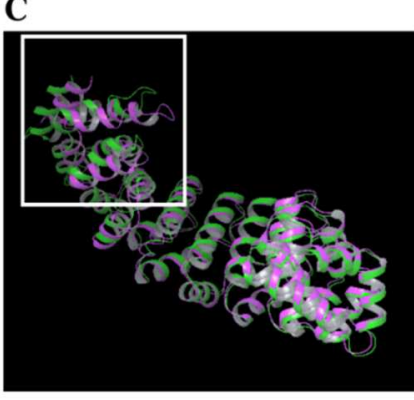

Fig. 2: A: The crystal structure of IMA3 in cargo free state with an open loop at the NLS Major Site (PDB ID: 6BVZ). B: The crystal structure of Hendra virus W protein C-terminus (the loop in golden color) in complex with IMA3 crystal form 2 rendering closed loop at NLS Major Site (PDB ID: 6BWA). C: The superimposed conformers of cargo bounded and free structures
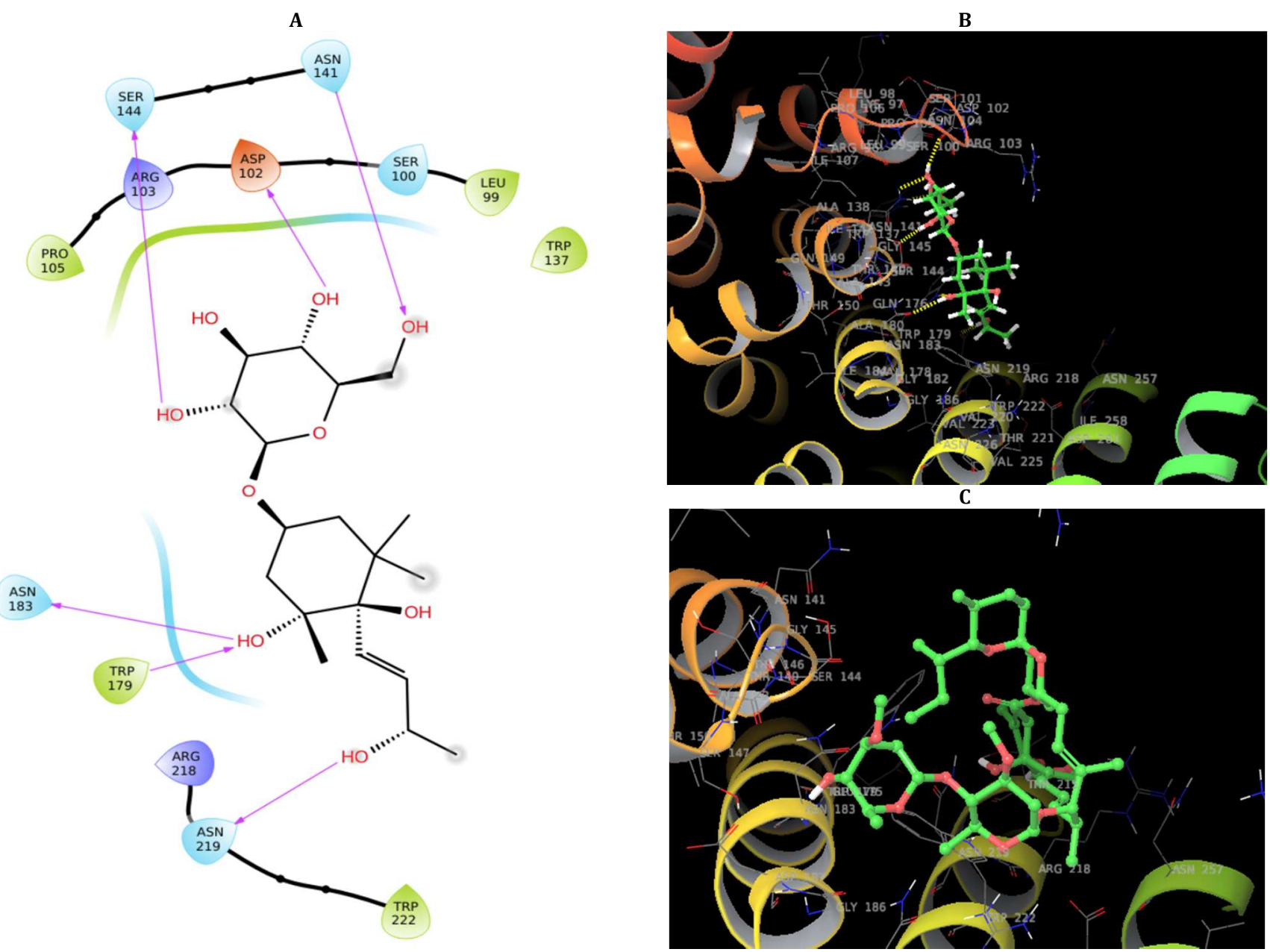

Fig. 3: Molecular interaction of ligands with at NLS major binding site on human IMA3 (PDB ID: 6BWA). A: Two-Dimensional (2D) representation of ATRI001 interaction with IMA3 facilitated by $6 \mathrm{H}$-bonds shown in pink arrow. B: Three dimensional (3D) illustration of ATRI001 interaction with IMA3 facilitated by $6 \mathrm{H}$-bonds shown in yellow dotted lines. C: Three dimensional (3D) illustration of Ivermectin interaction with IMA3 facilitated phobic enclosures but no H-Bonds 


\section{Molecular docking}

The molecular docking study was performed to understand the molecular interaction of plant molecules with human IMA3. Initial HTVS screening suggested 13,000 molecules with reasonable interaction with IMA3, and further, the shortlisted molecules were docked in the standard precision mode where the accuracy of prediction is better than the HTVS mode [50].

The docking in SP mode has suggested 20 top molecules as lead molecules. As ivermectin is reported to inhibit IMA3 mediated cargo nuclear import, it was also subjected to subsequent docking in extra precision (XP) mode. All 20 plant molecules showed better interaction than ivermectin with IMA3. However, the lowest energy ligand-bound conformers are always energetically favorable [51]. Hence, the plant molecule ATRI001 with the lowest binding energy-7.290 Kcal/mol was identified as a potent inhibitor of IMA3 by displaying better interactions with NLS site on human IMA3 by forming 6 H-bonds with Asp102, Asn141, Ser144, Trp179, Asn183 and Asn219 as shown in fig. 3A and 3B.

ATRI001 is a glycoconjugate having (2R,3R,4S,5S,6R)-6-Ethyloxane$2,3,4,5$-tetrol as a monosaccharide sugar group and connected to phyto-moiety $\quad(1 \mathrm{R}, 2 \mathrm{R}, 4 \mathrm{~S})-1-[(3 \mathrm{R})-3$-Hydroxybut-1-enyl]-2,6,6trimethylcyclohexane-1,2,4-triol through glycosidic linkage. The interaction of sugar group with IMA3 is facilitated by $3 \mathrm{H}$-bonds, two of them were formed by donating electrons to side-chain atoms of Asn141 and Ser144, one of $3 \mathrm{H}$-bonds was formed by accepting the electron from backbone atoms of Asp102. Whereas interaction between photo-moiety and IMA3 was established by means of $3 \mathrm{H}$ bonds, two of them were formed by donating electrons to side-chain atoms of Asn183 and Asn219, remaining H-bond found formed by accepting the electron from backbone atoms of Asp102. Ivermectin, a known IMA3 inhibitor, showed its lowest biding energy-4.946 $\mathrm{Kcal} / \mathrm{mol}$ at its lowest energy conformation without any hydrogen bonds, as shown in fig. 3C. Hence, the interaction of ATRI001 was found better than ivermectin by using three parameters: fitting at NLS binding site, low interaction penalties, and a good number of bonded interactions.

\section{CONCLUSION}

The Comparative analysis to evaluate the IMA3 inhibition activity of Ivermectin and plant small molecules using in silico approaches suggested that a plant molecule ATRI001 is superior to Ivermectin. Our in silico experiment shows ATRI001 can block the nuclear import of SARS-Cov-2 cargo. These predictions, however, require further investigations.

\section{FUNDING}

Nil

\section{AUTHORS CONTRIBUTION}

All the authors have contributed equally.

\section{CONFLICT OF INTERESTS}

The study was funded by Atrimed Pharmaceuticals, Bangalore. Latha Damle is the founder of Atrimed Biotech LLP and holds equity in Atrimed Pharmaceuticals. Shiban Ganju and Hrishikesh Damle hold equity in Atrimed Pharmaceuticals. Bharath BR is an employee of Atrimed Biotech LLP.

\section{REFERENCES}

1. Kanaan A, Raiaan K. Novel coronavirus (2019-NCOV): disease briefings. Asian J Pharm Clin Res 2020;13:22-7.

2. Leon C, Julian DD, Mike GC, David AJ, Kylie MW. The FDAapproved drug ivermectin inhibits the replication of SARS-CoV2 in vitro. Antiviral Res 2020;178:10478.

3. Raymond RR, Rowland, Vinita C, Ying F, Andrew P, Maureen K, et al. Intracellular localization of the severe acute respiratory syndrome coronavirus nucleocapsid protein: the absence of nucleolar accumulation during infection and after expression as a recombinant protein in vero cells. J Virol 2005;79:11507-12.

4. Khalid AT, Qingjiao L, Linbai Y, Yingchun Z, Jing L, Yi Z, et al. Nuclear/nucleolar localization properties of C-terminal nucle- ocapsid protein of SARS coronavirus. Viral Res 2005;114:2334.

5. Wulan WN, Heydet D, Walker EJ, Gahan ME, Ghildyal R. Nucleocytoplasmic transport of nucleocapsid proteins enveloped RNA viruses. Front Microbiol 2015;6:553.

6. Hiscox JA, Wurm T, Wilson L, Britton P, Cavanagh D, Brooks G. The coronavirus infectious bronchitis virus nucleoprotein localizes to the nucleolus. J Virol 2001;75:506-12.

7. Wurm T, Chen H, Hodgson T, Britton P, Brooks G, Hiscox JA. Localization to the nucleolus is a common feature of coronavirus nucleoproteins, and the protein may disrupt host cell division. J Virol 2001;75:9345-56.

8. Frieman M, Yount B, Heise M, Kopecky Bromberg SA, Palese $P$, Baric RS. Severe acute respiratory syndrome coronavirus ORF6 antagonizes STAT1 function by sequestering nuclear import factors on the rough endoplasmic reticulum/Golgi membrane. J Virol 2007;81:9812-24.

9. Macara IG. Transport into and out of the nucleus. Microbiol Mol Biol Rev 2001;65:570-94.

10. Bednenko J, Cingolani G, Gerace L. Nucleocytoplasmic transport: navigating the channel. Traffic 2003;4:127-35.

11. Stewart M. Molecular mechanism of the nuclear protein import cycle. Nat Rev Mol Cell Biol 2007;8:195-208.

12. Goldfarb DS, Corbett AH, Mason DA, Harreman MT, Adam SA. Importin alpha: a multipurpose nuclear-transport receptor. Trends Cell Biol 2004;14:505-14.

13. Cingolani G, Petosa C, Weis K, Muller CW. Structure of importin- $\beta$ bound to the IBB domain of importin- $\alpha$. Nature 1999;399:221-9.

14. Milles S, Mercadante D, Aramburu IV, Jensen MR, Banterle $\mathrm{N}$, Koehler C, et al. Plasticity of an ultrafast interaction between nucleoporins and nuclear transport receptors. Cell 2015;163:734-45.

15. Lee SJ, Matsuura Y, Liu SM, Stewart M. Structural basis for nuclear import complex dissociation by RanGTP. Nature 2005;435:693-6.

16. Moroianu J, Blobel G, Radu A. Nuclear protein import: ran-GTP dissociates the karyopherin alphabeta heterodimer by displacing alpha from an overlapping binding site on beta. Proc Natl Acad Sci 1996;93:7059-62.

17. Kutay U, Bischoff FR, Kostka S, Kraft R, Gorlich D. Export of importin alpha from the nucleus is mediated by a specific nuclear transport factor. Cell 1997;90:1061-71.

18. Bischoff FR, Gorlich D. RanBP1 is crucial for the release of RanGTP from importin $\beta$-related nuclear transport factors. FEBS Lett 1997;419:249-54.

19. Kobe B. Autoinhibition by an internal nuclear localization signal revealed by the crystal structure of mammalian importin

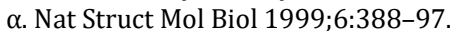

20. Fontes MR, Teh T, Kobe B. Structural basis of recognition of monopartite and bipartite nuclear localization sequences by mammalian importin- $\alpha$. J Mol Biol 2000;297:1183-94.

21. Min-Hsuan C, Iris BE, Gregory M, Nancy WK, Peter JS, Gino C. Phospholipid scramblase 1 contains a nonclassical nuclear localization signal with a unique binding site in importin $\alpha$. J Biol Chem 2005;280:10599-606.

22. Giesecke A, Stewart M. Novel binding of the mitotic regulator TPX2 (target protein for Xenopus kinesin-like protein 2) to importin- $\alpha$. J Biol Chem 2010;285:17628-35.

23. Rajeshwer S, Sankhala RK, Lokareddy, Salma B, Ruth $\mathrm{AP}$, Richard EG, et al. Three-dimensional context rather than NLS amino acid sequence determines importin $\alpha$ subtype specificity for RCC1. Nat Commun 2017;8:979.

24. Zhujun A, Kallesh DJ, Binchen W, Yingfeng Z, Sam K, Eric R, et al. Importin $\alpha 3$ interacts with HIV-1 integrase and contributes to HIV-1 nuclear import and replication. J Virol 2010;84:8650-63.

25. Shaw ML, Cardenas WB, Zamarin D, Palese P, Basler CF. Nuclear localization of the Nipah virus $\mathrm{W}$ protein allows for inhibition of both virus-and toll-like receptor 3-triggered signaling pathways. J Virol 2005;79:6078-88.

26. Audsley MD, Jans DA, Moseley GW. Nucleocytoplasmic trafficking of Nipah virus $W$ protein involves multiple discrete interactions with the nuclear import and export machinery. Biochem Biophys Res Commun 2016;479:429-33. 
27. Pumroy RA, Ke S, Hart DJ, Zachariae U, Cingolani G. Molecular determinants for nuclear import of influenza A PB2 by importin $\alpha$ isoforms 3 and 7. Structure 2015;23:374-84.

28. Wei X, Megan RE, Dominika MB, Alicia RF, Anuradha M, Joshua $\mathrm{BA}$, et al. Ebola virus VP24 targets a unique NLS binding site on karyopherin alpha 5 to selectively compete with the nuclear import of phosphorylated STAT1. Cell Host Microbe 2014;16:187200.

29. Nardozzi J, Wenta N, Yasuhara N, Vinkemeier U, Cingolani G. Molecular basis for the recognition of phosphorylated STAT1 by importin $\alpha 5$. J Mol Biol 2010;402:83-100.

30. Watson. Dietary components and immune function. Medicine 2010;3:421-68.

31. Moriarty RM, Surve BC, Naithani R, Chandersekera SN, Tiwari V, Shukla D. Synthesis and antiviral activity of Abyssinone II analogs. IACS National Meeting, Chicago, IL; 2007. p. 25-9.

32. Jingxu G, Kexin H, Feng W, Leixiang Y, Yubing F, Haibo L, et al. Preparation of two sets of 5,6,7-trioxygenated dihydroflavonol derivatives as free radical scavengers and neuronal cell protectors to oxidative damage. Bioorg Med Chem 2009;17:3414-25.

33. Ren $\mathrm{Q}$, Song $\mathrm{X}$. Use of a composition containing dihydromyricetin and myricetin in preparation of antiviral medicines. Faming Zhuanli Shenqing Gongkai Shuomingshu 2005;20:33.

34. Andersen OM, Helland DE, Andersen KJ. Anthocyanidin and anthocyanidin derivatives, and their isolation, for treatment of cancer, diseases caused by lesions in connective tissues, and diseases caused by viruses. PCT Int Appl 1997;5:121.

35. Wen CC, Kuo YH, Jan JT, Liang PH, Wang SY, Liu HG, et al. Specific plant terpenoids and lignoids possess potent antiviral activities against severe acute respiratory syndrome coronavirus. J Med Chem 2007;50:4087.

36. Sastry GM, Adzhigirey M, Day T, Annabhimoju R, Sherman W. Protein and ligand preparation: parameters, protocols, and influence on virtual screening enrichments. J Comput Aid Mol Des 2013;27:221-34.

37. Hwang S, Son SW, Kim SC, Kim YJ, Jeong H, Lee D. A protein interaction network associated with asthma. J Theor Biol 2008;252:722-31

38. Jacobson MP, Pincus DL, Rapp C, Day TJF, Honig B, Shaw DE, et al. A hierarchical approach to all-atom protein loop prediction. Proteins 2004;55:351-67.
39. Harathi P, Satyavati D, Deepak RG, Vivekananda B, Rajendra PV. Design synthesis of novel acridine tagged pyrazole derivatives as aurora kinase inhibitors. Asian J Pharm Clin Res 2020;13:7885.

40. Shivakumar D, Williams J, Wu Y, Damm W, Shelley J, Sherman W. Prediction of absolute solvation free energies using molecular dynamics free energy perturbation and the OPLS force field. J Chem Theory Computer 2010;6:1509-19.

41. Dagan Wiener A, Nissim I, Ben AN. Bitter or not? bitter predict, a tool for predicting taste from chemical structure. Sci Rep 2017;7:12074.

42. Friesner RA, Murphy RB, Repasky MP, Frye LL, Greenwood JR, Halgren TA, et al. Extra precision glide: docking and scoring incorporating a model of hydrophobic enclosure for proteinligand complexes. J Med Chem 2006;49:6177-96.

43. Raman K. Construction and analysis of protein-protein interaction networks. Sci Rep 2019;9:4980.

44. Hwang S, Son SW, Kim SC, Kim YJ, Jeong H, Lee D. A protein interaction network associated with asthma. J Theor Biol 2008;252:722-31.

45. Masahiro OK, Yoshihiro Y. Importin $\alpha$ : functions as a nuclear transport factor and beyond. Proc Japan Acad Ser B Phys Biol Sci 2018;94:259-74.

46. Nakielny S, Dreyfuss G. Import and export of the nuclear protein import receptor transportin by a mechanism independent of GTP hydrolysis. Curr Biol 1998;8:89-95.

47. Kalderon D, Roberts BL, Richardson WD, Smith AE. A short amino acid sequence able to specify nuclear location. Cell 1984;39:499-509.

48. Jiao Y, Liang Z, Ling X, Jian L, Lihua Y, Wenran D, et al. Nuclear import of NLS-RAR $\alpha$ is mediated by importin $\alpha / \beta$. Cell Sig 2020;69:1-11.

49. Elena C, Marc U, Lore L, Gunter B, John K. Crystallographic analysis of the recognition of a nuclear localization signal by the nuclear import factor karyopherin $\alpha$. Cell 1998;94:193-204.

50. Niraj KJ, Pravir K. Molecular docking studies for the comparative analysis of different biomolecules to target hypoxiainducible factor-1 $\alpha$. Int J Appl Pharm 2017;9:83-9.

51. Megan LP, Raul ZC, Marc CN. Conformational energy range of ligands in protein crystal structures: the difficult quest for accurate understanding. J Mol Recognit 2017;30:1-32. 